\title{
Toz Metalurjisi ile Üretilen Şekil Hafızalı NiTi Alaşımlarında Nb Parçacık İlavesinin Mikroyapı ve Sertlik Üzerine Etkisi
}

\author{
Hakan GÖKMEŞE ${ }^{1 *}$, Hakan Burak KARADAĞ ${ }^{2}$, Naci Arda TANIŞ ${ }^{3}$ \\ ${ }^{1}$ Konya Necmettin Erbakan Üniversitesi, Seydişehir Ahmet Cengiz Mühendislik Fakültesi, Makine Mühendisliği \\ Bölümü, 42370, Konya \\ ${ }^{2}$ Konya Necmettin Erbakan Üniversitesi, Mühendislik ve Mimarlık Fakültesi, Metalurji ve Malzeme Mühendisliği \\ Bölümü, 42360, Konya \\ ${ }^{3}$ Kırlkkale Üniversitesi, Mühendislik ve Mimarllk Fakültesi, Metalurji ve Malzeme Mühendisliği Bölümü, 71100, \\ Kirlkkale \\ (ORCID:0000-0003-0053-8444) (ORCID: 0000-0003-1045-7277) (ORCID: 0000-0001-5547-9790)
}

\begin{abstract}
$\ddot{O} z$
$\mathrm{Bu}$ çalışmada, toz metalürjisi yöntemi kullanılarak NiTi esaslı şekil bellekli alaşımı üzerinde $\mathrm{Nb}$ alaşım elementinin etkileri araştırılmıştır. Bu amaçla NiTi tozlarına ağırlıkça \%1, 2 ve 4 takviye oranında $\mathrm{Nb}$ tozları ilave edilerek, toz karışımları hazırlanmıştır. Hazırlanan NiTi-Nb toz karışımları, gezegen (planetary) tipi ögütme cihazında 1 saat süreyle karıştırılmıştır. Toz karıştırma işlemini takiben NiTi ve NiTi-Nb toz karışımları çift etkili presleme cihazı kullanılarak, $1000 \mathrm{MPa}$ 'da presleme işlemine tabii tutulmuştur. Presleme işlemi sonrası deney numuneleri argon atmosferi altında, $1180^{\circ} \mathrm{C}$ sicaklıkta 1 saat sinterlenmiştir. Toz malzeme ve sinterlenen deney numunelerinin mikro yapı ve faz dönüşümlerinin tespit edilmesi amacıyla, X-1şını kırınım yöntemi (XRD), element dağılım spektrometresi (EDS) ve taramalı elektron mikroskobu (SEM) çalışmalarda kullanılmıştır. NiTi ve NiTi-Nb deney numunelerinin sertliği, Vickers (HV0.5) mikro sertlik ölçüm yöntemi kullanılarak tespit edilmiştir. Nb takviye oranın artışıyla NiTi alaşımı yoğunluk ve sertlik değerinde artış meydana geldiği belirlenmiştir.
\end{abstract}

Anahtar kelimeler: NiTi, Nb, toz metalürjisi, mikro yapı, sertlik.

\section{Effect on Microstructure and Hardness of Nb Particle Addition in NiTi Shape Memory Alloys Produced by Powder Metallurgy}

\begin{abstract}
In this study, the effects of $\mathrm{Nb}$ alloy element on NiTi based shape memory alloy were investigated by using powder metallurgy method. For this purpose, powder mixtures were prepared by adding $\mathrm{Nb}$ powders at the ratio of 1,2 and $4 \%$ by weight to NiTi powders. The NiTi-Nb powder mixes prepared were mechanically ground for 1 hour in a planetary grinding device. After mechanical grinding process, NiTi and NiTi-Nb powder mixtures were compressed under 1000MPa pressure by using double action pressing device and afterwards, the test samples were sintered under an argon atmosphere at $1050{ }^{\circ} \mathrm{C}$ for 1 hour. X-ray diffraction (XRD), elemental distribution spectrometry (EDS) and scanning electron microscope (SEM) were used to determine microstructure and phase transformations of powder materials and sintered test samples. The hardness of the NiTi and NiTi-Nb test samples were determined using the Vickers (HV0.5) micro hardness measurement method. An increase in density and hardness of NiTi alloy with the increase of $\mathrm{Nb}$ additive ratio was determined.
\end{abstract}

Keywords: NiTi, Nb, powder metallurgy, microstructure, hardness.

"Sorumlu yazar: hakan1440@gmail.com

Geliş Tarihi: 03.09.2020, Kabul Tarihi: 27.09.2020 


\section{Giriş}

Toz metalurjisi (TM), metal işleme teknolojileri arasında yer alan hasssas üretim teknolojileri arasında yer almaktadır. Bu yöntem boyutları ve şekilleri önceden belirlenmiş ve iyi paketlenme özelliğine sahip metal tozların sağlam, hassas ve yüksek performanslı parçalar haline getirilmesi işlemidir. Bu işlem sırasında; ön alaşımlı veya karıştırılmış tozlar bir kalıba doldurularak, istenilen şekilde preslenir ve daha sonrasında ham numuneler atmosfer kontrollü bir firında yüksek sıcaklıkta dayanımı kazandırılır [1, 2].

Toz metalurjisi yöntemi özellikle parça üretim açısından sağladığı kolaylıklar sayesinde, birçok demir esaslı ve demir dışı metal karakterli malzemelerde olduğu gibi, NiTi alaşımlarının üretiminde de kullanılan yaygın bir yöntemdir [3].

Son zamanlarda üstün özelliklere sahip olan akıllı malzemeler mühendislik, tarım, uzay, havacılık gibi pek çok alan başta olmak üzere çeşitli uygulama alanlarında tercih sebebi olabilmektedir. Birçok uygulama alanı ve bu uygulama alanlarına yönelik olarak farklı akıllı malzeme çeşitleri bulunmaktadır. Özellikle şekil hafızalı alaşımlar, uygulanan büyük deformasyonların etkisi altında sıcaklık değişimi veya gerilim yoluyla malzeme şekil ve özelliklerinin geri kazanılabildiği alaşımlardır $[4,5]$. Nitinol olarak isimlendirilen şekil hafızalı alaşımlar, Ni ve Ti oranları açısından birbirine benzer kimyasal kompozisyonlarda üretilebilmektedir. Bu malzemeler eşsiz şekil hafiza özellikler, iyi bir sönümleme etkisi, iyi bir aşınma ve korozyon direnci göstermektedirler. Aynı zamanda NiTi alaşımlarının kullanılması ve tercih nedeni, Ni-Ti'nin çoklu tek yönlü şekil hafızası, iki yönlü şekil hafızası veya psödoelastik dönüşüm yetenekleri olmasıdır. Bu özelliklerinden dolayı son zamanlarda geniş bir şekilde kullanılabilmektedirler. Özellikle bu alaşımlar endüstriyel ve bilhassa tıbbi uygulamalarda çoğunlukla yer bulmaktadırlar [6]. Gözenekli yapıda olan nikel titanyum alaşımları biyomedikal uygulamalar için ümit verici biyomalzemelerdir. Yüksek darbe sönümleme kapasiteleri, süperelastiklik ve canlı dokuların büyümesini sağlayan ayarlanabilir eşit dağılmış gözenekli yapıya sahip olması nedeniyle sert doku implantı olarak tercih edilmektedirler [7, 8]. Bu alaşımların üretiminde çoğunlukla döküm ve toz metalürjisi teknolojileri kullanılabilmektedir [9, 10]. Ancak döküm teknolojisinde küçük parça boyutlu ve karmaşık geometriye sahip şekil hafizalı parçaların maliyeti ve imalatı zor olabilmektedir. Bu durumların yanı sıra üretim sırasında ergitilmiş NiTi alaşımı ve havada yer alan oksijen birlikteliği, Ti elementi ile çökelti fazı ortaya koyarak, malzeme içerisinde istenmeyen çökelti fazlarının oluşumuna sebep olabilmektedir [11]. Döküm yönteminden farklı olarak toz metalurjisi (TM) ile üretilen gözenekli NiTi alaşımların kompozisyon kontrolü sağlanabilmektedir. Daha önceki yapılan çalışmalar NiTi alaşımının kimyasal kompozisyonunun önemli olduğunu ortaya koymuştur. Çünkü martenzit↔östenit dönüşüm sıcaklığı alaşımdaki nikel oranına bağlıdır [12]. Bununla birlikte bu yöntem ile sonraki talaşlı işlemleri büyük ölçüde ortadan kaldırılarak, son şekil veya son şekle yakın olan karmaşık şekillerde, kontrol edilebilir gözenekli yapıya sahip parçaların seri üretimi sağlanır, döküm sırasında segregasyon nedeniyle meydana gelebilecek hatalar ise önlenmiş olur [13]. $\mathrm{Bu}$ durum çoğunlukla NiTi alaşımları üretiminde döküm teknolojisinin yanı sıra toz metalürjisi teknolojisinin de tercih edilme sebebidir [10].

Yapılan araştırmalarda NiTi şekil hafızalı alaşımın kimyasal bileşiminin değişiminin yanı sıra, üçüncü bir kimyasal elementin mikro yapı, mekanik ve termal histeresis etkisi üzerine çalışılmaktadır. Mühendislik alanındaki uygulamaları hedefleyen NiTi şekil hafızalı alaşımlara eklenen en uygun elementler $\mathrm{Cu}, \mathrm{Pd}, \mathrm{Fe}, \mathrm{Pt}, \mathrm{Nb}, \mathrm{Al}, \mathrm{Hf}, \mathrm{Zr}$ olarak gösterilebilir [14]. Bu elementlerden toz metalürjisi tekniği ile özellikle $\mathrm{Nb}$ takviyesi ile hazırlanan NiTi alaşımları üzerine çalışmalar neredeyse yok denecek kadar azdır. NiTi ikili sisteminde dönüşüm sıcaklıkları Ti/Ni oranına bağlıdır ve \%0.1 Ni konsantrasyonu artışıly yaklaşık $10{ }^{\circ} \mathrm{C}^{\prime}$ lik bir azalma gerçekleşir. NiTi sisteminde $\mathrm{Nb}$ ile alaşımlandırma Ms sıcaklığını düşürmektedir. Süperelastisite, mikro yapı özellikleri (martenzit dönüşümü ve gözenekli malzeme NiTiNb tabakası) ve mekanik özelliklerin anlaşılabilmesi, NiTi alaşımı üzerinde yoğunlaşılan konular arasında devam etmektedir $[15,16]$.

Böylece bu çalışma kapsamında, son zamanlarda çoğunlukla tercih sebebi olan akıl malzemeler arasında yer alan NiTi şekil bellekli alaşımları çalışılmıştır. Toz metalürjisi tekniği ile üretimin yanı sıra geleceğin metalleri arasında yer alan Niyobyum $(\mathrm{Nb})$ takviyesinin NiTi alaşımının, mikro yapı ve mekanik özellikleri üzerindeki etkisi araştırılmıştır. 


\section{Materyal ve Metot}

$\mathrm{Bu}$ çalışmada ticari olarak temin edilen NiTi alaşımı ve Nb tozları kullanılarak, TM metodu ile deney numuneleri üretilmiştir. Üretilen NiTi-Nb alaşımında kullanılan NiTi tozlarının boyutu yaklaşık $14 \mu \mathrm{m}$ ve $\mathrm{Nb}$ tozlarının boyutu ise $43 \mu \mathrm{m}$ 'dir.

NiTi alaşım tozlarına ağırlıç̧a \%1, 2 ve 4 takviye oranlarında $\mathrm{Nb}$ ilave edilerek hazırlanan toz karışımları, gezegen tip ögütücü de homojen dağılımının sağlanması amacıyla 1 saat mekanik olarak karıştırma işlemine tabii tutulmuş̧ur. NiTi tozlar ile üç farklı oranda karıştııılan başlangıç tozları, presleme cihazında $1000 \mathrm{MPa}$ basınç altında sıkıştırılarak ham deney numuneleri üretilmiştir. Üretilen NiTi ve NiTi-Nb toz metal numuneler, çalışmada kullanılan kalıp ve presleme cihazı Şekil 1a ve b'de gösterilmiştir. Ø10x15 mm boyutlarında preslenen deney numuneleri, $10^{\circ} \mathrm{C} / \mathrm{dk}$. hızda çalışan atmosfer kontrollü 1 sıl işlem firını kullanılarak Argon gaz akışı altında, $1050{ }^{\circ} \mathrm{C}$ sıcaklıkta 1 saat sinterlenerek yüksek sıcaklık dayanımı kazandırılmıştır. Sinterlenen toz metal deney numunelerinin yoğunluk ölçümleri için Micromeritics-Accupyc2 1340 marka Helyum Piknometresi kullanılmıştır. Her bir deney numunesinde en az 5 ölçüm yapılarak ortalama yoğunluk sonuçları elde edilmiştir.

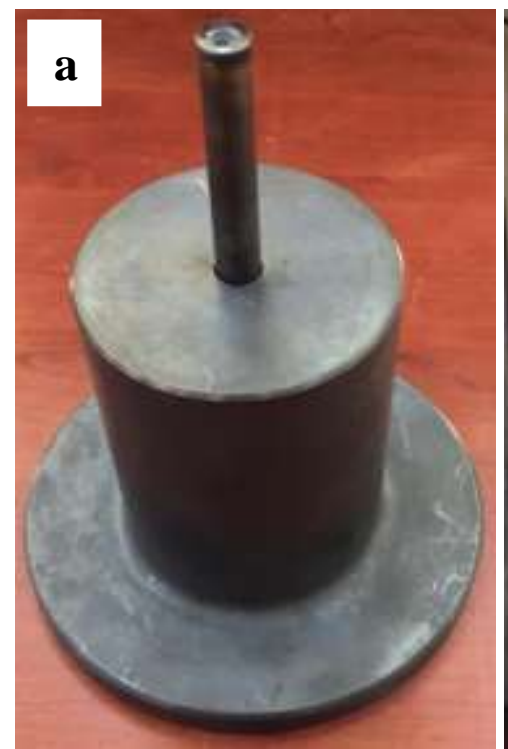

Şekil 1. Metal kalıp (a) ve presleme cihazı (b)

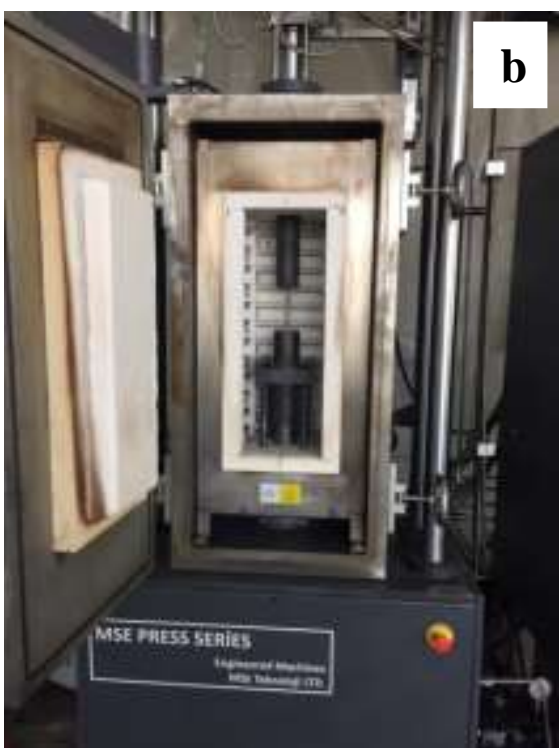

Deney numunelerinin özellikle $\mathrm{Nb}$ ilavesi sonrası gerek NiTi gerekse $\mathrm{Nb}$ fazının yanı sıra oluşması muhtemel diğer fazların tespiti amacıyla XRD analizi uygulanmıştır. Deney numunelerinin faz kompozisyonları, XRD (X-ray diffraction) tekniği ile Rigaku D/Max-2200 cihazı kullanılarak Cu-2 $\alpha$ $(1.54060 \AA)$ radyasyonu ve $2 \Theta=10-90^{\circ}, 20-60 \mathrm{kV}$ ile analiz edilmiştir. Deney numunelerinin yoğunluk ölçümleri sonrası sırasıyla zımparalama ve parlatma işlemlerini takiben $\mathrm{HF}, \mathrm{HNO} 3$ ve saf su kullanılarak hazırlanan çözelti ile numunelerin dağlama işlemleri gerçekleştirilmiştir. Genel metalografi çalışmaları sonrası deney numunelerinin mikroyapısal karakterizasyonu için optik mikroskop ve taramalı elektron mikroskobu (SEM) çalışmalarda kullanılmıştır. Bununla birlikte SEM cihazı ile bağlantılı çalışan enerji dağılımlı spektrometre (EDS) kullanılarak, mikroyapı odaklı elementel analiz ölçümleri yapılmıştır. Çalışmanın son aşamasında mikroyapı incelemelerini takiben, mikro vickers (HV 0.5) sertlik ölçüm işlemi uygulanmıştır.

\section{Bulgular ve Tartışma}

NiTi-Nb toz metal alaşımlarının üretimi için başlangıçta kullanılan NiTi ve Nb tozlarının SEM görüntüsü Şekil 2'de verilmiştir. Başlangıç toz malzemelerin SEM görüntüleri incelendiğinde, atomize NiTi tozlarının (Şekil 2a) küresel şekil, Nb tozlarının (Şekil 2b) ise düzensiz şekil morfolojisinde yer aldığı görülmektedir. 

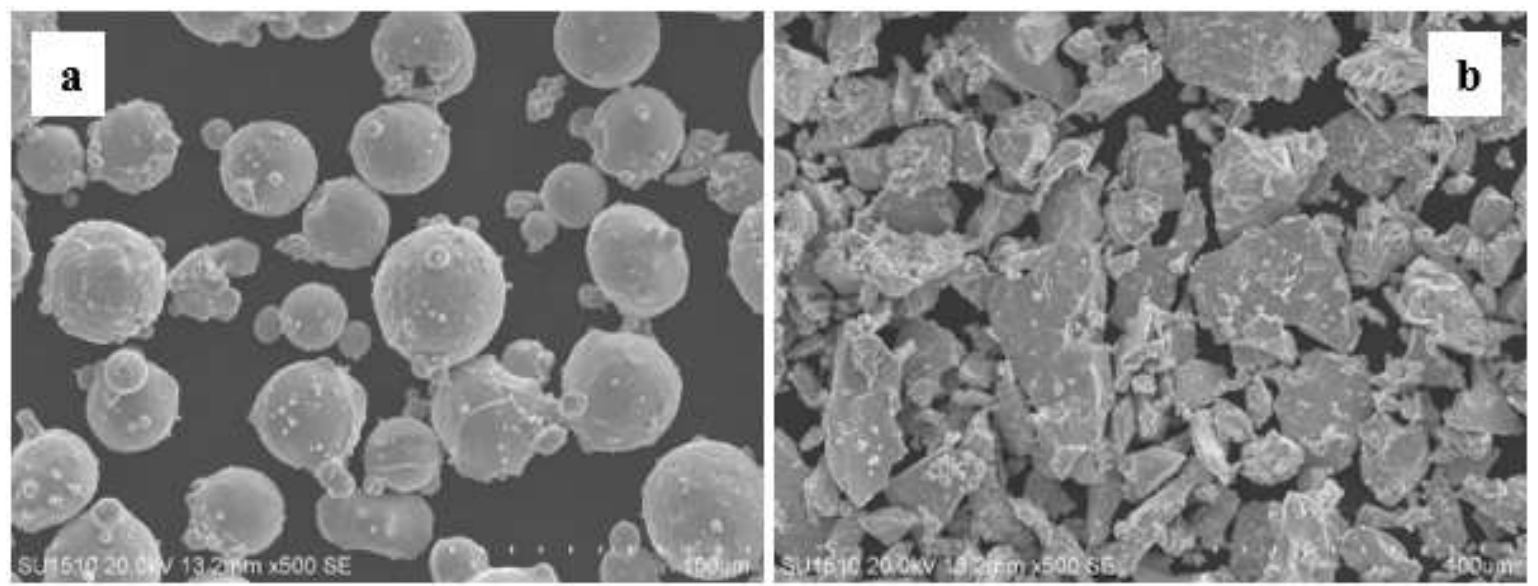

Şekil 2. Başlangıç toz malzemelerin SEM görüntüsü; a) NiTi, b) Nb

NiTi alaşımı (\%0) ve \%1, 2 ve 4 (ağırlıkça) Nb takviye oranına sahip NiTi-Nb alaşımlarının, sinterleme sonrası elde edilen yoğunluk sonuçları Şekil 3'de verilmiştir. Numunelerin yoğunlukları \%0 takviye oranından \%4 takviye oranına doğru artış gösterdiği belirlenmiş̧tir. Buna göre sinterleme sonras1 yoğunluk artışında $8,57 \mathrm{~g} / \mathrm{cm}^{3}$ yüksek yoğunluklu $\mathrm{Nb}$ alaşım elementinin etkili olduğu düşünülebilir. Belirtilen üretim parametreleriyle elde edilen bu oran, toz metalürjisi metodu ile üretilen $\mathrm{NiTi}-\mathrm{Nb}$ alaşımları açısından istenilen seviyede olduğunu göstermektedir [17].

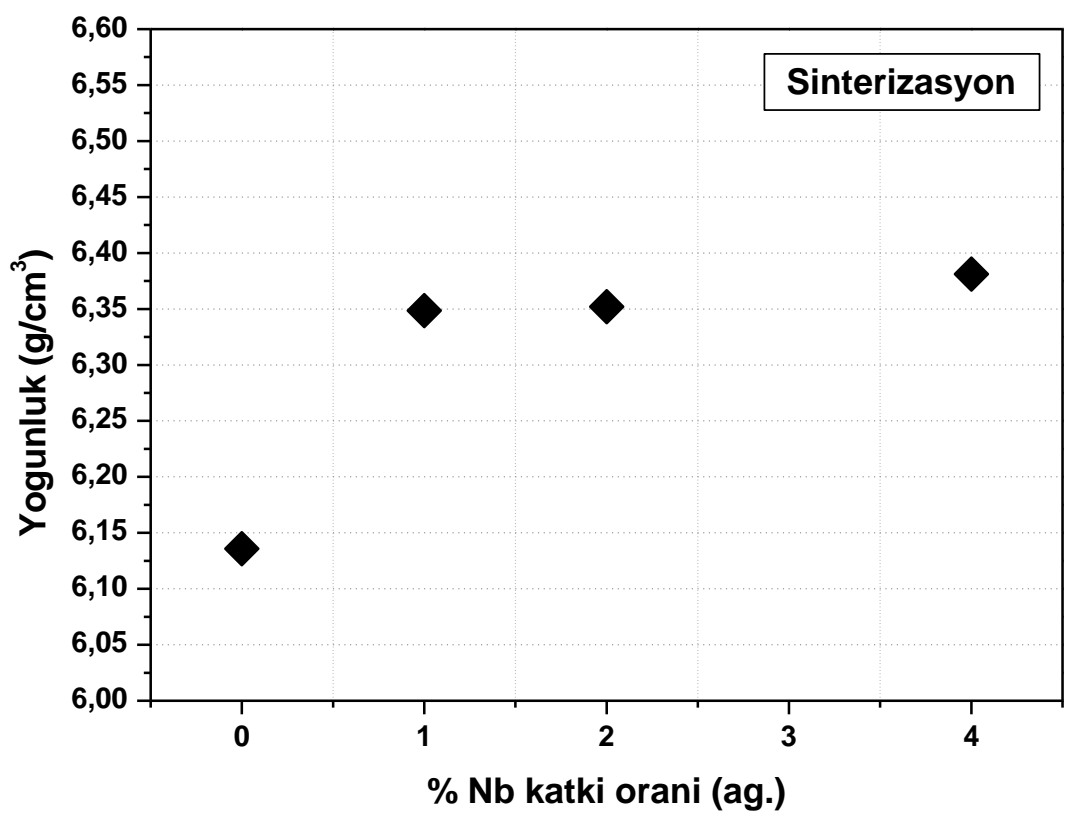

Şekil 3. NiTi-Nb alaşımının yoğunlukları

Sinterleme işlemi sonrası optik mikroskop mikroyapı görüntüleri Şekil 4'te gösterilmiştir. Şekil 4 'te verilen mikro yapı görüntüleri incelendiğinde, taneler arasındaki boyun oluşumunun istenilen düzeyde olduğu [18], nihai yapı içerisinde oluşan gözeneklerin yapıs1 ve dağılımı da açık bir biçimde görülmektedir. Gözeneklerin etrafında görülen sarı renkli kısımlarda titanyumca zengin fazların oluştuğu ve gözenek içerisinde hapsolan oksijenin sebebiyle titanyumun oksitlenerek sarı renkte olduğu anlaşılmaktadır. Tanış ve arkadaşlarının [3] bakır ilaveli NiTi şekil bellekli alaşımlar ile ilgili yaptıkları benzer bir çalışmada, SEM - EDS analiz sonuçları bu görüşle benzerlik göstermektedir. Numunelerde gözenek yapısı incelendiğinde, basınç altında tanelerin yönlendiği ve gözeneklerin belli alanlarda toplandığı görülmüştür. Oluşan gözeneklerin boyu 150-200 mikrometre arasındadır. 

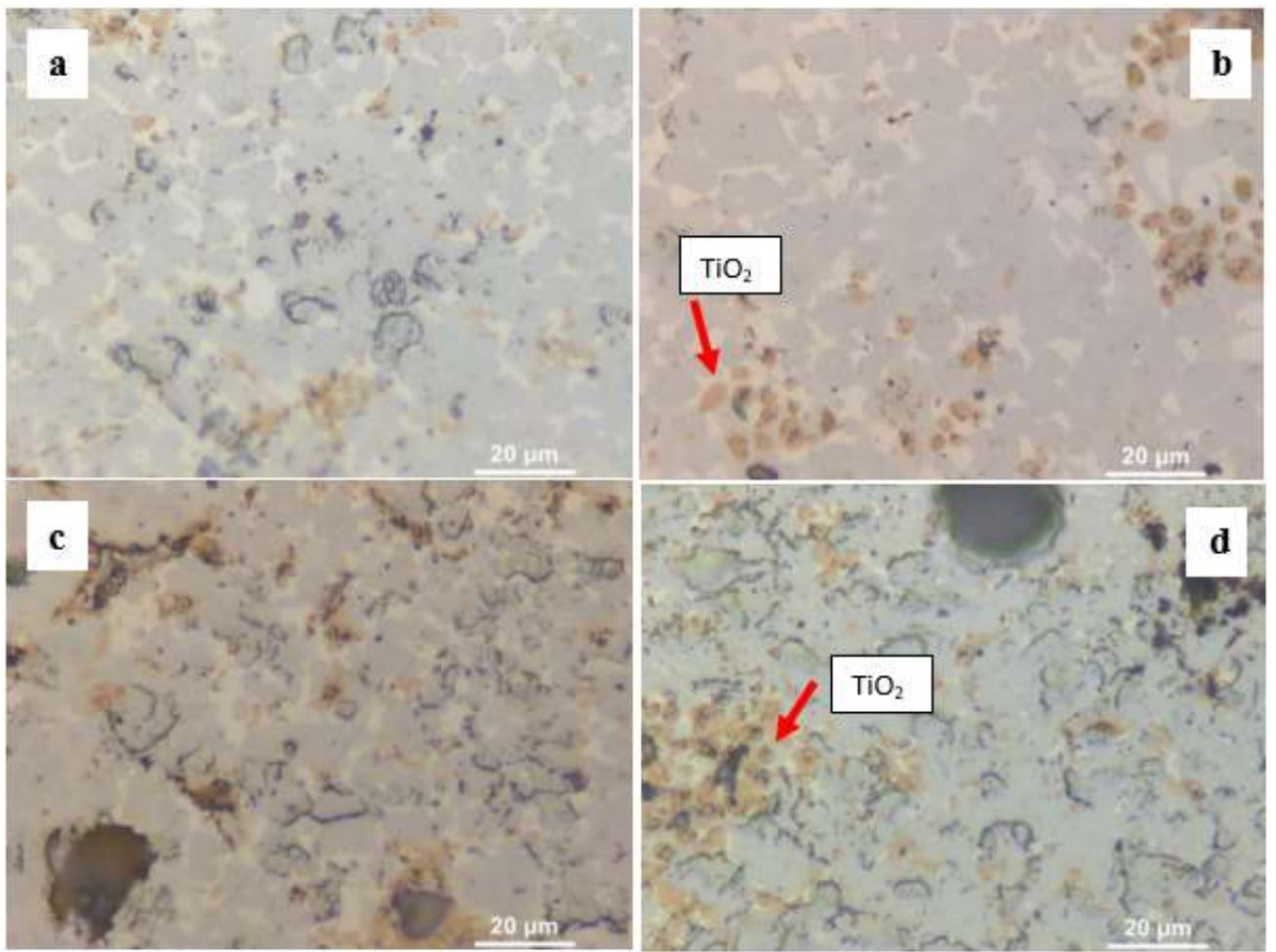

Şekil 4. NiTi-Nb alaşım mikroyapı görüntüleri; a) NiTi, b) $\% 1 \mathrm{Nb}$, c) $\% 2 \mathrm{Nb}$, d) $\% 4 \mathrm{Nb}$

Şekil 5'te ağ. \% 0, 1, 2 ve $4 \mathrm{Nb}$ eklenen numunelerin SEM görüntüleri verilmiştir. Şekil 5a'da $\mathrm{Nb}$ takviyesi olmayan NiTi alaşım mikro yapı görüntüsünde, açık gri olan nikelce zengin Ni3Ti fazı, Şekil 5b ve c'deki sırasıyla ăg.\%1 ve $2 \mathrm{Nb}$ eklenmiş NiTi alaşımlarına göre daha az görülmektedir. NiTi fazı ise takviyesiz numunede matrisin tamamını oluştururken, \%1 ve $2 \mathrm{Nb}$ takviyeli numunelerde matrisin belirli bölgelerinde oluşmuştur. Şekil 5 d'de ağ. \%4 Nb eklenen NiTi alaşımında, NiTi fazı matrisin tamamını oluştururken, nikelce zengin fazın lamelimsi bir oluşuma benzer şekilde matris içerisinde dağılım gösterdiği anlaşılmaktadır.
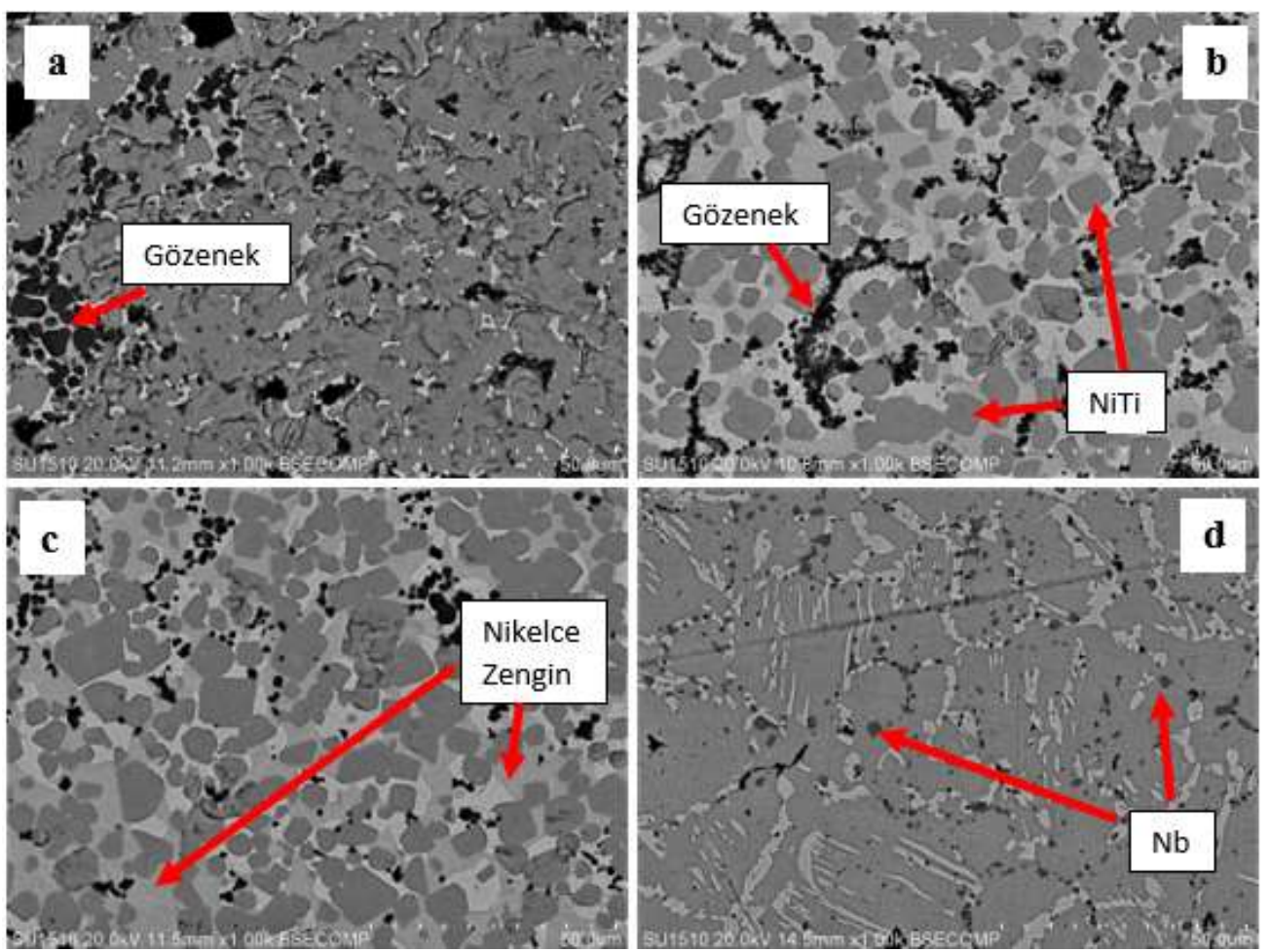

Şekil 5. NiTi-Nb alaşım mikroyapı görüntüleri; a) NiTi, b) \%1 Nb c) $\% 2 \mathrm{Nb}$ d) $\% 4 \mathrm{Nb}$ 
Şekil 6' da ağ. \%4 Nb takviyeli NiTi alaşımının genel EDS analizi yapılmış ve elementel haritası çıkarılmıştır. Genel EDS analizinde \%4 Nb takviyesi ile üretilen NiTi alaşımında, Nb dağılımının yer aldığı tespit edilmiştir. EDS harita dağılımı incelendiğinde, görüntü üzerinde açık gri olan bölgelerin nikelce zengin fazları tanımladığı açık bir şekilde görülmektedir. Ana yapıyı oluşturan gri bölgenin ise, eş atomik NiTi fazı olduğu belirlenmiş olup $\mathrm{Nb}$ tanelerinin nikelce zengin fazın etrafinda yer aldığı saptanmıştır. $\mathrm{Nb}$ tanelerinin nikelce zengin faz ile birleştiği belirlenirken, NiTi fazı ile tam olarak ıslanmamış ve gözeneklerin oluştuğu belirlenmiştir. NiTi-Nb alaşımları üzerine Yin ve ark. [19] yaptıkları çalışmada, SEM görüntüleri ve EDS analizlerinde matris içinde $\mathrm{Nb}$ zengin fazlarında oluştuğunu göstermişlerdir.
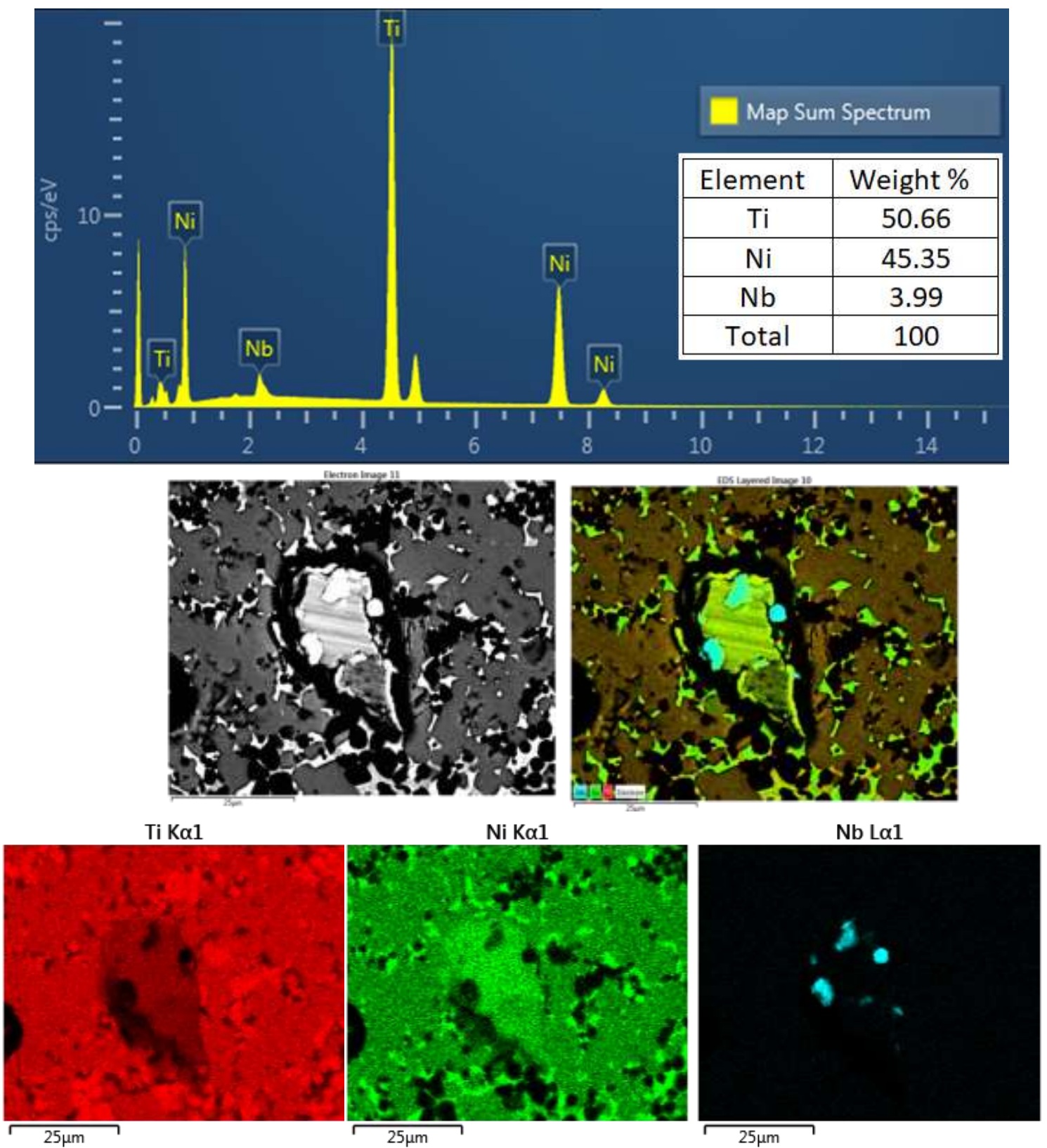

Şekil 6. $\mathrm{NiTi}-\% 4 \mathrm{Nb}$ alaşımının elementel analiz ve haritalama sonucu

Ağırlıkça \%4 Nb takviyesi içeren NiTi alaşımının XRD analiz sonucu Şekil.7'de verilmiştir. XRD analizi incelendiğinde, östenitik B2 fazının ve martenzitik B19' fazlarının oluştuğu gözlemlenmiş ve sonuçlar Şekil.6'da verilen EDS analiz sonuçlarını destekler niteliktedir. $\beta-\mathrm{Nb}$ fazı $36^{\circ}$ ve $70^{\circ} 2 \theta$ açılarında düşük şiddette pikler olarak tespit edilmiştir. Cronemberger ve ark. [20] NiTi alaşımına $\mathrm{Nb}$ takviyesi ile yaptıkları çalışma da Nb fazının XRD şiddetinin takviye oranı arttıkça arttığını belirlemiş 
ve en net sonuçları $\% 9$ takviye oranında bulmuşlardır. Şekil $5 \mathrm{~d}$ ve Şekil 6' da belirlenmiş olan açık gri renkte $\mathrm{Ni}_{3} \mathrm{Ti}$ fazının XRD pikleri de, analiz sonucunda şiddetli oldukları $2 \theta$ açılarında saptanmıştır.

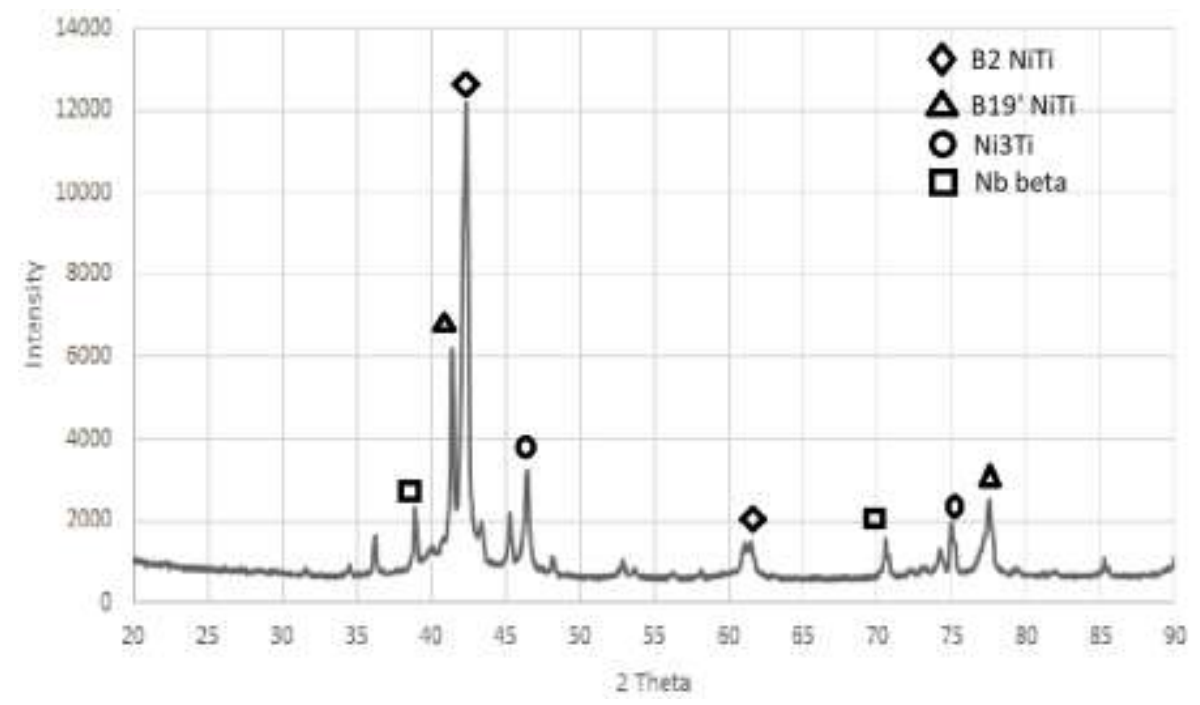

Şekil 7. NiTi-\%4Nb alaşımının XRD sonuçları

NiTi ve NiTi-Nb alaşımlarının mikro yapı incelemeleri ve analizleri neticesinde, elde edilen mikro sertlik sonuçları Şekil 8' de gösterilmiştir. Alaşımların mikro sertlik sonuçları incelendiğinde, $\operatorname{artan} \mathrm{Nb}$ takviye oranı ile sertlik değerinde artış olduğu saptanmıştır. Bu duruma mikroyapısal açısından, matris içerisinde $\mathrm{Nb}$ oranı yoğunluğunun artması ile oluşan gerilimin neden olduğu belirtilebilir. $\% 4 \mathrm{Nb}$ takviye oranı ile üretilen NiTi-Nb alaşımının sertlik değeri, takviyesiz NiTi alaşım sertlik değerine göre yaklaşı \%30 oranında artış gösterdiği belirlenmiştir. Liu ve ark. [21] yaptıkları çalışmada, daha yüksek takviye oranlarda $\mathrm{Nb}$ alaşım elementi ile çalışmışlar ve sertlik değerinin artan $\mathrm{Nb}$ oranı ile arttığını ifade etmişlerdir. Fakat elde ettikleri sertlik sonuçları bütün numuneler için yaptığımız çalışmaya oranla oldukça düşüktür. Bu çalışmada mikro sertlik sonuçlarının yüksek seyretmesi, Liu ve ark. kullandıkları ergitme yöntemi ile üretimin aksine ön alaşımlı küresel NiTi metal tozlarının kullanılması olarak öne sürülebilir. NiTi alaşımında \%1-3 ve $5 \mathrm{Cu}$ ilavesi yapılan benzer bir çalışmada, $\mathrm{Cu}$ parçacıklarının artışına bağlı olarak sertlik değerinin arttığı belirtilmiştir [22].

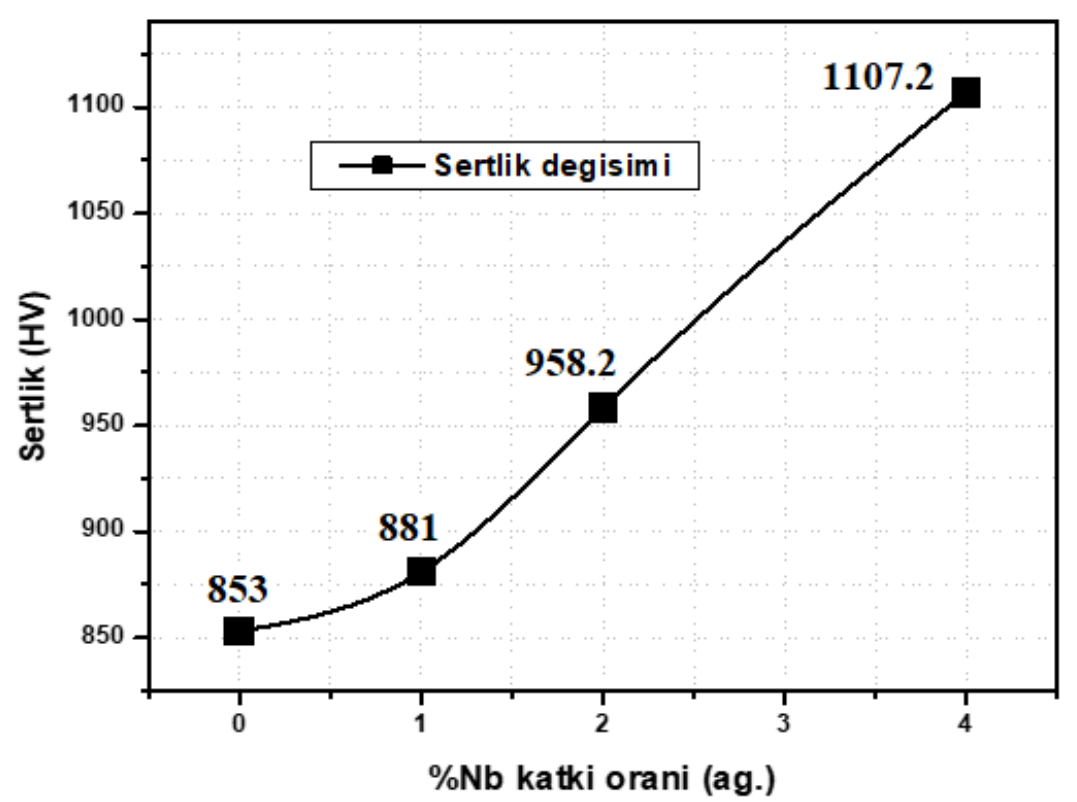

Şekil 8. Mikro sertlik sonuçları 


\section{Sonuç ve Öneriler}

$\mathrm{NiTi}-\mathrm{Nb}$ toz metal alaşımlarında, $\mathrm{Nb}$ parçacık takviyesinin NiTi alaşımı mikro yapısal karakterizasyonu ve sertlik özellikleri üzerindeki etkileri incelenmiştir. Deneysel çalışmalar ve deneysel bulgular göz önünde bulundurulduğunda, sonuçlar aşağıda belirtilmiştir.

NiTi alaşımına kıyasla $\mathrm{Nb}$ takviyesi ile üretilen toz metal alaşımlarda sinterleme sonrası yoğunluk değerleri yaklaşık \%50 oranında artış göstermiştir. Mikro yapısal açıdan Nb takviyesinin ön alaşımlı NiTi fazına difüze olduğu ve gözeneklerin etrafında titanyumca zengin fazların oluştuğu belirlenmiştir. Mikro yapıda gözeneklerin yaklaşık olarak 150-200 mikrometre civarında oluşum gösterdiği belirlenmiştir. Nikelce zengin fazın lamelimsi bir oluşum şeklinde matris içerisinde dağılım gösterdiği tespit edilmiştir. Yapılan genel EDS analizi ile, Nb takviyesinin matris içinde dağılımı görülmüştür. XRD analizi sonucuna göre, östenitik B2 fazının ve martenzitik B19' fazlarının oluştuğu ve ayrıca $\mathrm{Nb}$ fazının düşük şiddette pikler sergilediği tespit edilmiştir. NiTi alaşımına kıyasla $\% 4 \mathrm{Nb}$ takviyesi ile yaklaşık \%30 oranında mikro sertlik değerinde artış sağlandığg belirlenmiştir.

\section{Yazarların Katkısı}

Makale, yazarların birlikte katkıları ile ortaya çıkarılmıştır.

\section{Çıkar Çatışması Beyanı}

Yazarlar arasında herhangi bir çıkar çatışması bulunmamaktadır.

\section{Araştırma ve Yayın Etiği Beyanı}

Yapılan çalışmada araştırma ve yayın etiğine uyulmuştur.

\section{Kaynaklar}

[1] Gökmeşe H., Bostan B. 2013. Improvements of dry sliding wear behaviour and mechanical properties in $2014 \mathrm{Al}$ alloy by age-hardening. Sci Res Essays, 8 (45): 2227-2234.

[2] Gokmese H., Ozdemir M., Bostan B. 2015. The Characterization and Production by Gas Atomization Method of Pre-alloyed AA 2014 Powder Metal Aluminum. Int J Sci Technol Res., 1 (1): 2422-8702.

[3] Gökmeşe H., Tanış A., Bostan B. 2018. Effect of $\mathrm{Cu}$ addition on microstructure and mechanical properties of NiTi based shape memory alloy. International Advanced Researches and Engineering Journal, 2 (1): 20-26.

[4] Çakmak Ö., Kaya M. 2017. Akıllı Malzeme Şekil Hafızalı Alaşımların Termodinamiği. Nevşehir Bilim ve Teknoloji Dergisi, 6 (2): 541-555.

[5] Toptaş E., Akkuş N. 2007. Teknolojik araştırmalar: MTED 2007 (4) 15-22. Makine Teknolojileri Elektronik Dergisi, 4 (4): 15-22.

[6] Canbay C.A., Özkul İ. 2018. Yaşlandırma Süresinin TiNi Şekil Hafizalı Alaşımında Termodinamik Parametreler ve Yapısal Özellikler Üzerine Etkisinin İncelenmesi. Firat Üniversitesi Mühendislik Bilim Dergisi, 30 (2): 313-318.

[7] Li D.S., Zhang Y.P., Eggeler G., Zhang X.P. 2009. High porosity and high-strength porous NiTi shape memory alloys with controllable pore characteristics. J Alloys Compd., 470 (1-2): 5-9.

[8] Kaya M., Orhan N., Somunkiran İ. 2008. Effect of porosity on compressive strength of porous NiTi alloy fabricated by powder metallurgy. J Fac Eng Arch Gazi Univ., 23 (4): 931-936.

[9] Luo J., Bobanga J.O., Lewandowski J.J. 2017. Microstructural heterogeneity and texture of asreceived, vacuum arc-cast, extruded, and re-extruded NiTi shape memory alloy. J Alloys Compd., 712: 494-509.

[10] Shihab S.A., Salman K.D., Saud L.J. 2020. Studying Wear Behavior of Ni-Ti- Ag Shape Memory Alloy Synthesized by P/T, 38 (6): 846-853.

[11] Ternik P., Rudolf R. 2016. Numerical analysis of continuous casting of niti shape memory alloy. Int J Simul Model., 15 (3): 522-531. 
[12] Zhu S.L., Yang X.J., Hu F., Deng S.H., Cui Z.D. 2004. Processing of porous TiNi shape memory alloy from elemental powders by Ar-sintering. Mater Lett., 58 (19): 2369-2373.

[13] Li B.Y., Rong L.J., Li Y.Y. 1998. Anisotropy of dimensional change and its corresponding improvement by addition of $\mathrm{TiH} 2$ during elemental powder sintering of porous NiTi alloy. Mater Sci Eng A, 255 (1-2): 70-74.

[14] Sharma N., Jangra K.K., Raj T. 2018. Fabrication of NiTi alloy: A review. Proc Inst Mech Eng Part L J Mater Des Appl., 232 (3): 250-269.

[15] Fan Q.C., Zhang Y., Zhang Y.H, Wang Y.Y., Yan E.H., Huang S.K., Wen Y.H. 2019. Influence of $\mathrm{Ni} / \mathrm{Ti}$ ratio and $\mathrm{Nb}$ addition on martensite transformation behavior of NiTiNb alloys. $\mathrm{J}$ Alloys Compd., 790 (April): 1167-1176.

[16] Wang L., Xie L., Zhang L.C., Chen L., Ding Z., Lv Y., Zhang W., Lu W., Zhang D. 2018. Microstructure evolution and superelasticity of layer-like NiTiNb porous metal prepared by eutectic reaction. Acta Mater., 143 (November): 214-226.

[17] Chen Y., Jiang H., Rong L., Xiao L., Zhao X. 2011. Mechanical behavior in NiTiNb shape memory alloys with low $\mathrm{Nb}$ content. Intermetallics, 19 (2): 217-220.

[18] Tosun G., Kılıç M., Özler L., Tosun N. 2018. Characterization of a porous nickel-titanium alloy produced with self-propagating high-temperature synthesis. Materiali in tehnologije/Materials and technology, 52 (4): 435-442.

[19] Yin H., Ma G., Fan Q., Wang Y., Huang S., Yi Y. 2019. Thermal-induced phase transformation behavior of NiTiNb hypoeutectic, eutectic, and hypereutectic alloys. Metals (Basel), 9 (2): 214.

[20] Cronemberger M.E.R., Menezes V.H.F., Silva R da, Santos I.G.R., Sordi V.L., Kuri S.E., Rovere C.A.D., 2019. Effect of $\mathrm{Nb}$ Content in the Microstructural and Thermal Characteristics of NiTiNb Shape Memory Alloys. Mater Res., 22 (suppl 1): 1-7.

[21] Liu S., Han S., Wang L., Liu J., Tang H. 2019. Effects of Nb on the Microstructure and Compressive Properties of an As-Cast Ni44Ti44Nb12 Eutectic Alloy. Materials (Basel), 12 (24): 1-9.

[22] Kılıç M., Yenigün B., Serkan B., Balalan Z., Kırık İ. 2019. Effect of Cu addition on porous NiTi SMAs produced by self-propagating high-temperature synthesis. Mechanical Testing, 61 (12): 1140-1144. 